\title{
Research on Failure Behavior of 35CrMnSi based on Ballistic Experiment
}

\author{
Xu Yongjie'1, Wang Zhijun'1, Pan Shouli², Li Shuo² \\ 1 College of Mechatronic Engineering, North University of China, Taiyuan 030051, China
}

2208 Research Institute of China Ordnance Industries, Beijing 102202, China

Keywords: failure behavior; 35CrMnSi; ballistic experiment;scanning electron microscope

\begin{abstract}
Failure behavior of metal materials under impact loading has become key research content in industrial manufacturing field. Especially in the field of weapon research, 35CrMnSi dynamic figure behavior in the serving process attracts relevant weapon manufacture researchers' extensive attention. In order to study on failure behavior of 35CrMnSi under shock dynamic loading, obtained the damage mode of $35 \mathrm{CrMnSi}$ penetrating steel plate under condition of different impacting velocity by ballistic experiment. Results show that when impacting velocity is lower the $0.469 \mathrm{~km} / \mathrm{s}$, fragments emerge upsetting deformation only; when impacting velocity is between $0.574 \mathrm{~km} / \mathrm{s}$ and $1.280 \mathrm{~km} / \mathrm{s}$, fragments emerge fracture failure. Observe fractures of $35 \mathrm{CrMnSi}$ fragments using scanning electron microscopy (SEM), results show that when impacting velocity is higher than $0.574 \mathrm{~km} / \mathrm{s}, 35 \mathrm{CrMnSi}$ fragments present brittle dissociation transgranular fracture and also exist partial melting, adiabatic shear band, molten dimple and irregular particles size of $100 \mu \mathrm{m}$ in the fracture surface. The research results provide reference for 35CrMnSi failure behavior related research.
\end{abstract}

\section{Introduction}

Failure behavior of metal materials under strong impact load is the focus that material and weapons researchers pay close attention[1-4]. Some international researchers have been spread out study broadly on dynamic behavior of metal materials under strong impact load[5-9], P.K.Ray 、 A.G.Odeshi、 Rick L.Martineau have studied the dynamic mechanical properties and fracture failure mechanism of High Strength Low Alloy steel (High Strength Low Alloy, HSLA) in different heat treatment states through Hopkinson bar, ballistic rifle, and explosive expansion loop technology. At the same time, some chinese scholars have also studied on metal materials especially the dynamic mechanical properties of high strength low alloy steel step by step[10-12]. X.Zejian studied the fracture toughness of 30CrMnSi steel through experiment under the condition of strain rate $10^{2} \mathrm{~s}^{-1}$. L.Jinquan discovered 35CrMnSi steel penetrator emerge micro cracks in the head under the condition of $1.200 \mathrm{~km} / \mathrm{s}$ speed shock impact through experiment. Come so far, dynamic fracture failure research on HSLA steel under the condition of high pressure and high strain rate $\left(10^{4} \mathrm{~s}^{-1} \sim\right.$ $10^{6} \mathrm{~s}^{-1}$ ) , experimental tests are mainly considered in the study process. The experiments introduced above are all belong to qualitative experiment, but they do not analysis material fracture failure behavior under different speed testing conditions.

As a kind of widely used high strength low alloy steel at the international level, 35CrMnSi steel not only used in manufactures key components, for example, large aircraft landing gear and wing girder, but also applied to the penetrating warhead shell material in field of weapons industry. Do experiment of 35CrMnSi fragment penetrator impacting steel plate by ballistic rifle, and obtain the damage model of $35 \mathrm{CrMnSi}$ fragment under the condition of testing speed range $0.469 \mathrm{~km} / \mathrm{s} \sim 0.1280 \mathrm{~km} / \mathrm{s}$. Microscopic observe and fracture analysis the fracture appearance of 35CrMnSi fragment penetrator under different impacting speed through scanning electron microscopy. 


\section{Experimental System}

According to reference[13], double quenching and low temperature tempering can improve alloy steel strength, and improving steel toughness. The study experiment adopts 35CrMnSi after double quenching and low temperature tempering, its chemical constituents as shown in Table 1 and mechanical properties as shown in Table 2.

Table 1: Chemical constituents of 35CrMnSi

\begin{tabular}{|c|c|c|c|c|c|}
\hline \multirow{2}{*}{ Material } & \multicolumn{5}{|c|}{ Chemical component / \% } \\
\hline & $\mathrm{C}$ & $\mathrm{Mn}$ & $\mathrm{Si}$ & $\mathrm{Cr}$ & Others \\
\hline 35CrMnSi & $0.320 \sim 0.390$ & $0.800 \sim 1.100$ & $1.100 \sim 1.400$ & $1.100 \sim 1.400$ & $<0.105$ \\
\hline \multicolumn{6}{|c|}{ Table 2: Mechanical properties of 35CrMnSi } \\
\hline $\begin{array}{l}\text { Density } \\
\mathrm{g} / \mathrm{cm}^{3}\end{array}$ & $\begin{array}{c}\text { Elongation } \\
\%\end{array}$ & $\begin{array}{c}\text { Hardness } \\
\text { HRC }\end{array}$ & $\begin{array}{c}\text { Yield strength } \\
\mathrm{MPa}\end{array}$ & \multicolumn{2}{|c|}{$\begin{array}{c}\text { Tensile strength } \\
\mathrm{MPa}\end{array}$} \\
\hline 7.85 & $10.20 \sim 10.80$ & 51.00 & $1310.00 \sim 1400.00$ & \multicolumn{2}{|c|}{$1760.00 \sim 1790.00$} \\
\hline
\end{tabular}

Considering the speed range of 35CrMnSi fragment penetrator impact on target steel, $14.5 \mathrm{~mm}$ caliber ballistic rifle was selected in the process experiment[14], according to length-diameter ratio of fragment in typical warheads, design 35CrMnSi cylindrical fragment, size for $11.2 \mathrm{~mm} \times 40.0 \mathrm{~mm}$, and mass $30.0 \mathrm{~g}$, as shown in Figure 1. Launch method is subcaliber shooting, separation technology of fragment from sabot by aerodynamic principle, test bullet as shown in Figure 2.

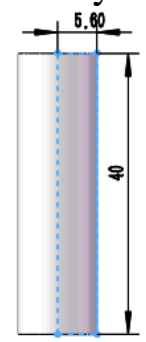

a. size of fragment

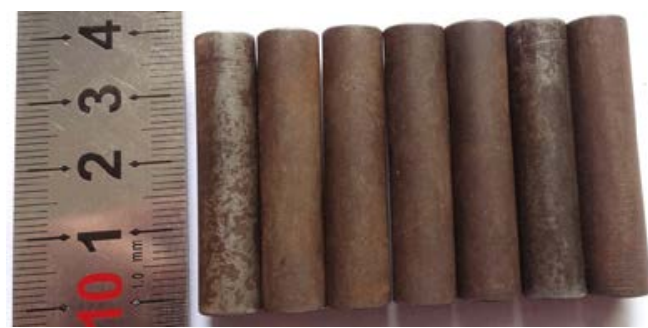

b. test fragments

Figure 1: Test fragments

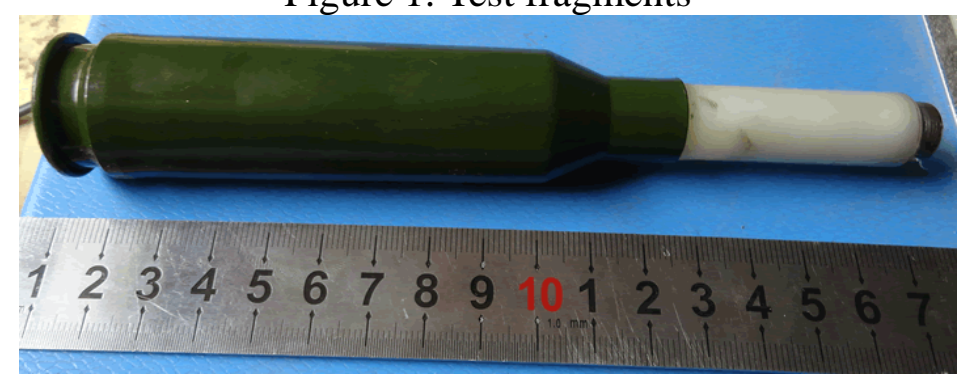

Figure 2: Test bullet

$14.5 \mathrm{~mm}$ caliber ballistic rifle, velocity measuring device, and recycling equipment compose the experimental system[15]. Place the support frame perpendicular to the ground upright in the position away from the muzzle $2.0 \mathrm{~m}$, and fix the target plate on the support from in the position as high as muzzle vertical location, put laser target before and after the target plate with distance of $0.5 \mathrm{~m}$, put the recycling equipment in $1.0 \mathrm{~m}$ back of the target plate, specific testing arrangement as shown in Figure 3. 


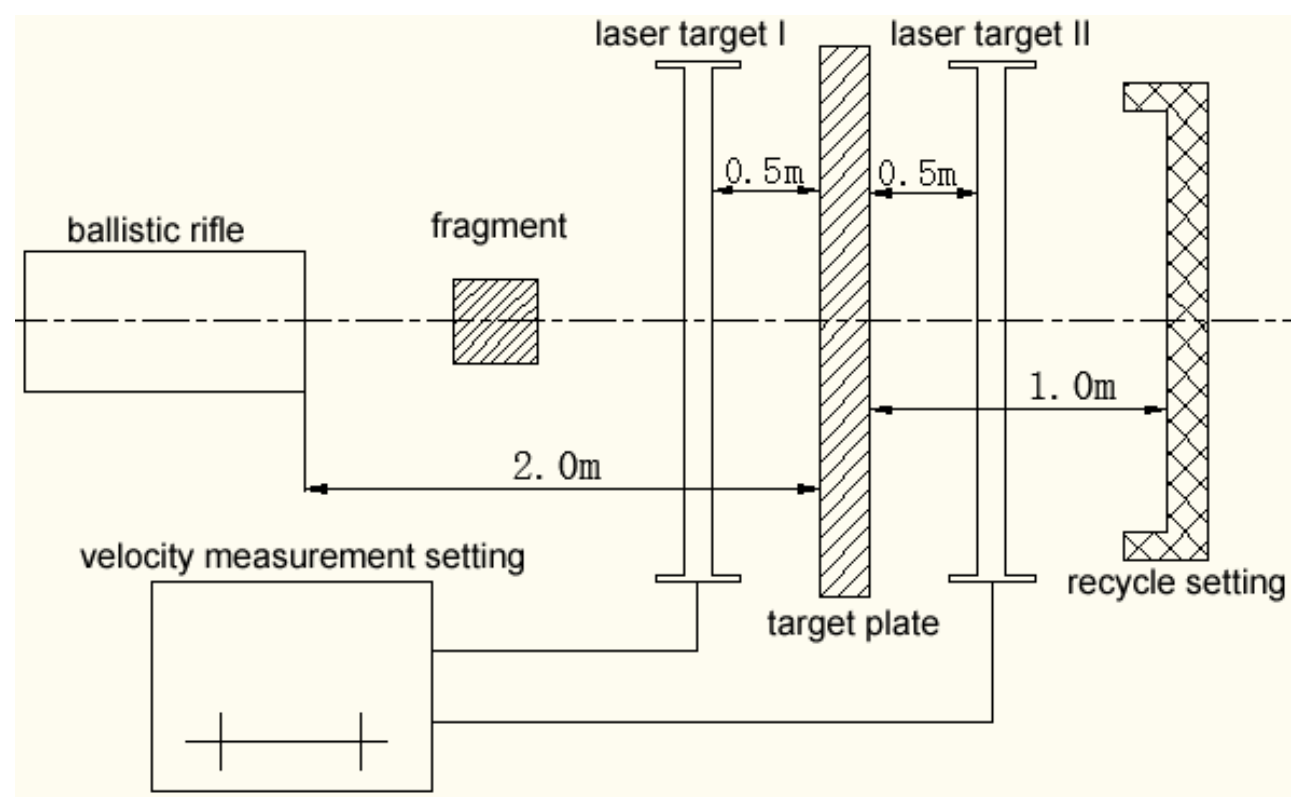

Figure 3: Testing arrangement

Target plate uses the $10.0 \mathrm{~mm}$ thick low carbon steel plate[16], control fragment speed by changing quantity of gun propellant, and obtain impact speed by laser velocity measurement setting.

\section{Experimental Results and Analysis}

Take the experimental data that fragment stable flight before hitting the target plate as effective data. Select 6 testing 35CrMnSi fragments in the effective speed range, recycle and statistics their mass characteristic, the results is shown in Table 3. 
Table 3: Mass characteristic of recycled fragments

\begin{tabular}{|c|c|c|c|c|c|}
\hline$\underset{r}{\text { Numbe }}$ & $\begin{array}{l}\text { Impact } \\
\text { speed } \\
/ \mathrm{km}^{\mathrm{s}-1}\end{array}$ & Recycled fragment & $\begin{array}{c}\text { Residual } \\
\text { mass } \\
\text { /g }\end{array}$ & $\begin{array}{c}\text { Residual } \\
\text { length } \\
\text { /mm }\end{array}$ & Macroscopic morphology \\
\hline$\# 1$ & 0.469 & & 30.10 & 36.70 & upsetting deformation \\
\hline \#2 & 0.574 & & 24.60 & 34.30 & $\begin{array}{l}\text { shear fracture, fracture } \\
\text { smooth and no obvious } \\
\text { plastic deformation }\end{array}$ \\
\hline \#3 & 0.656 & & 22.10 & 30.90 & $\begin{array}{l}\text { preventatives white fracture, } \\
\text { brittle fracture, appear local } \\
\text { oxidation zone }\end{array}$ \\
\hline$\# 4$ & 0.673 & 8 & 21.80 & 31.40 & $\begin{array}{l}\text { the upper part is white } \\
\text { surface, the lower part is } \\
\text { obvious ablated }\end{array}$ \\
\hline$\# 5$ & 0.722 & & 23.40 & 33.00 & $\begin{array}{l}\text { fracture is roughly } 45^{\circ} \text { shear } \\
\text { stress direction, } \\
\text { preventatives light plastic } \\
\text { deformation, and fracture } \\
\text { surface is uneven }\end{array}$ \\
\hline \#6 & 1.280 & & 19.60 & 28.60 & $\begin{array}{l}\text { fracture is roughly } 45^{\circ} \text { shear } \\
\text { stress direction, and fracture } \\
\text { surface oxy-genated } \\
\text { seriously }\end{array}$ \\
\hline
\end{tabular}

The final analysis conclusion can be concluded as follow:

1) Impact stress increases with the increase of impact speed, less than $0.469 \mathrm{~km} / \mathrm{s}, 35 \mathrm{CrMnSi}$ fragment only emerges upsetting deformation, above $0.574 \mathrm{~km} / \mathrm{s}, 35 \mathrm{CrMnSi}$ fragment emerges fracture failure.

2) By comparing the mass and length of the recycling 35CrMnSi fragment, mass and length reduce sharply along with impact speed increase.

3) It can be concluded from macroscopic morphology that $35 \mathrm{CrMnSi}$ fragment emerges shear brittle fracture accompanied by local high temperature oxidation under testing condition more than $0.574 \mathrm{~km} / \mathrm{s}$ impact speed.

\section{Fracture Microstructure Analysis}

Heat treated 35CrMnSi steel has features of high strength and high hardness[17]. Therefore the35CrMnSi fragment is not easy to break but emerges upsetting deformation on a macro-scale under testing conditions of low speed and low impact load. When the impact speed is higher than $0.574 \mathrm{~km} / \mathrm{s}$, high temperature, high pressure and high strain areas form in the penetrator-target interface under strong impact load, then it leads to fracture damage. In order to study failure mechanism of 35CrMnSi steel under the condition of strong dynamic impact load, observe and analysis fracture of 35CrMnSi fragment using scanning electron microscopy, the result is shown in Figure 4. 


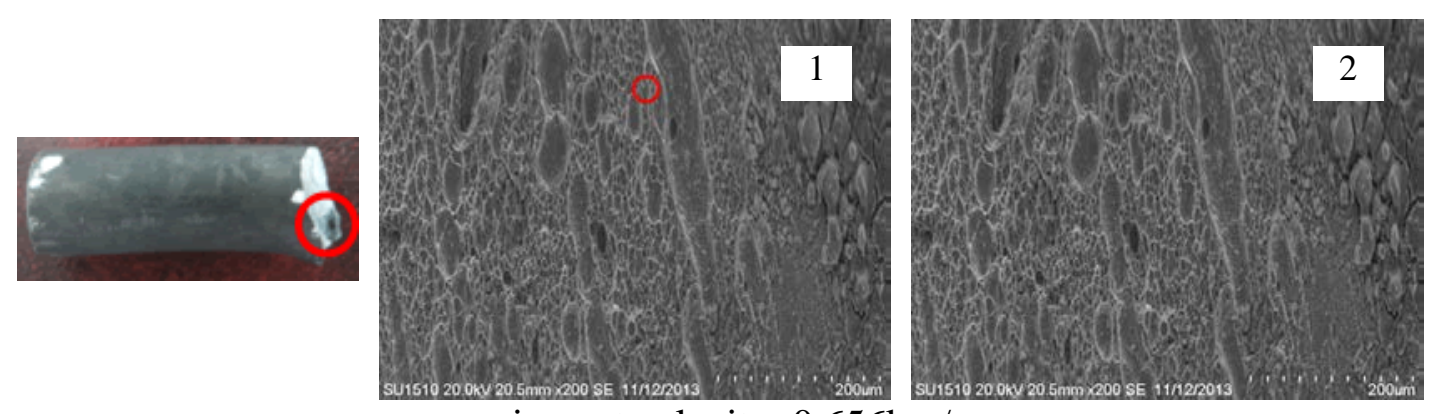

a. impact velocity: $0.656 \mathrm{~km} / \mathrm{s}$


b. impact velocity: $0.671 \mathrm{~km} / \mathrm{s}$

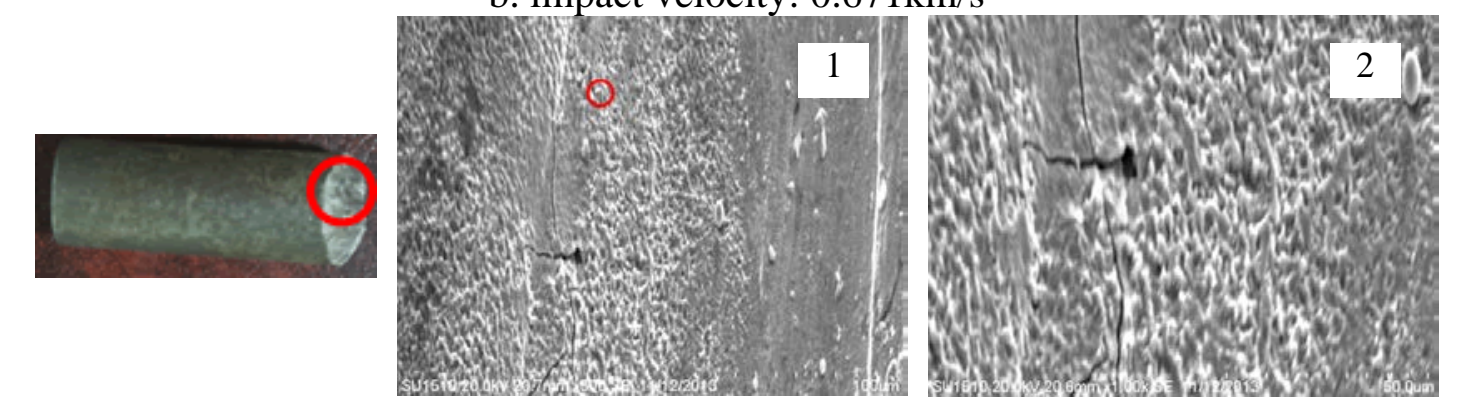

c. impact velocity: $0.574 \mathrm{~km} / \mathrm{s}$


d. impact velocity: $1.280 \mathrm{~km} / \mathrm{s}$

Figure 4: SEM photographs of recycled fragments

\section{Fracture Model under Strong Impact Load}

In Figure 4-a1, dimple fracture is small size and shallow depth. According to reference[18], dimple fracture large size and deep depth fully shows good toughness and plastic deformation, on the contrary, the material toughness is poor. Small size and shallow depth dimple fracture declare heat treated 35CrMnSi steel shows poor toughness under high speed impact. Also observe the dimple fracture shape in Figure 4-a2, it is elongated type shear caused by shear plastic deformation.

Observe fracture microstructure in Figure 4-b1, it is typical dissociation fracture, main microscopic characteristics is a flat mirror. The cracks cross parallel each other and different height dissociation surfaces and from dissociation steps, the Figure 4-b2 shows typical dissociation steps. The characteristics of dissociation fracture illustrate $35 \mathrm{CrMnSi}$ fragment emerges brittle transgranular fracture.

According to the analysis typical morphology and macrostructure in Figure 4-a and Figure 4-b, $35 \mathrm{CrMnSi}$ fracture mode is dissociation transgranular fracture and show poor toughness under testing condition of strong dynamic impact load.

\section{Analyses of Adiabatic Shear Band and Melting Phenomenon}

Heat treated 35CrMnSi has characteristics of high hardness, poor toughness and poor 
deformation ability, according to analysis above that 35CrMnSi fracture mode is shear fracture.

The white long-thin ribbons in Figure 4-c1 inner the red circle, combination material high temperature and high pressure status under strong dynamic impact load, and severe shear plastic deformation impedes thermal dissipation then cause material softening in the slip line, the process can be considered as adiabatic, thus the adiabatic shear band formed.

The emergence of adiabatic shear band led to materials bearing capacity decrease and even lost, so crack extension along with the direction of adiabatic shear band, as shown in Figure 4-c2, the secondary cracks emerge along with the direction of the adiabatic shear band. In addition, there are molten dimple components in both sides of adiabatic shear band, and direction of dimple is consistent with adiabatic shear band.

Strong impact load leads high temperature environment formation in the fracture, causes molten dimple in the fracture surface, and causes irregular coagulation particle size of 100 microns after melted, as shown in Figure 4-d1 and Figure 4-d2.

\section{Conclusions}

From the experiments and analysis on failure behavior of $35 \mathrm{CrMnSi}$, the following conclusions can be obtained.

(1) $14.5 \mathrm{~mm}$ caliber ballistic rifle used for the ballistics experiment, it can provide effective shooting speed, and satisfy the requirements of the material performance test, and the velocity data laser velocimeter provided is real, effective and high reliability.

(2) Accelerate the 35CrMnSi fragment penetrator by ballistic rifle, when impact speed higher than $0.574 \mathrm{~km} / \mathrm{s}$, the fragment emerges fracture failure, fracture macroscopic morphology characterized by shear brittle fracture, and accompanied by local high temperature oxidation.

(3) The 35CrMnSi fragment's fracture microstructure was observed through scanning electron microscope and find that the brittle type fracture mode mainly is dissociation fracture. Strong dynamic impact load causes lots of heat thus lead formation of high temperature product such as adiabatic shear band, molten particulate matter and molten dimple.

(4) Comparing the scanning electron microscope photographs, it can be seen that degree of fracture surface oxidation when the impact speed is $1.280 \mathrm{~km} / \mathrm{s}$ is higher than other three groups. That is, with the increase of impact speed, the more serious degree of oxidation in fracture.

\section{Conflict of Interests}

The authors declare that there is no conflict of interests regarding the publication of this paper.

\section{References}

[1] N. Jian-Guo, S. Wei-Dong, R. Hui-Lan, and M. Tian-Bao, "Response and protection of materials and structures under impact loadings",Chinese Journal of Solid Mechanics,vol.31,no.5, pp.532-552, 2010.

[2] M. Alkhader, and L. Bodelot, "Large strain mechanical behavior of HSLA-100 steel over a wide range of strain rates,” Journal of Engineering Materials and Technology, vol.134, pp.011005-1-011005-8,2012.

[3] K. Maweja, and W. Stumpf, "The design of advanced performance high strength low-carbon martensitic armour steels,” Materials Science and Engineering A485, pp.140-153, 2008.

[4] Pradipta Kumar Jena, Bidyapati Mishra, K. Siva Kumar, and T. Balakrishna Bhat, "An experimental study on the ballistic impact behavior of some metallic armour materials against 7.62 mm deformable projectile,” Materials and Design, vol.31,pp.3308-3316, 2010.

[5] A.G. Odeshi, M.N. Bassim, and S.Al-Ameeri, "Effect of heat treatment on adiabatic shear bands in a high-strength low alloy steel," Materials Science and Engineering A419, pp.69-75,2006.

[6] Rick L. Martineau, Michale B. Prime, and Thomas Duffey, "Penetration of HSLA-100 steel 
with tungsten carbide spheres at striking velocities between 0.8 and $2.5 \mathrm{~km} / \mathrm{s}$,” International Journal of Impact Engineering, vol.30, pp.505-520, 2004.

[7] P.K. Ray, R.I. Ganguly, and A.K. Panda, "Optimization of mechanical properties of an HSLA-100 steel through control of heat treatment variables," Materials Science and Engineering A346, pp.122-131, 2003.

[8] P.K. Jena, Bidyapati Mishra, M. RameshBabu, Arvindha Babu, A.K. Singh, K. SivaKumar, and T. Balakrishna Bhat, "Effect of heat treatment on mechanical and ballistic properties of a high strength armour steel,” International Journal of Impact Engineering, vol.30, pp.505-520, 2004.

[9] K. Cho, Y.C.Chi, and J. Duffy, "Microscopic observations of adiabatic shear bands in three different steels,” Metallurgical Transactions A, vol.21A, pp.1161-1175,1990.

[10] X. Ze-Jian, L. Yu-Long, L.Yuan-Yong, L. Jing-Run, and C. Yu-Ze, "Mode II dynamic fracture toughness of two high strength steels under high loading rate," Acta Metallurgica Sinica, vol.42,no.6,pp.635-640,2006.

[11] X. Ze-Jian, L.Yu-Long, L. Na, and L. Yuan-Yong, "Effect of loading rate on mode I dynamic fracture toughness of high strength steels 40Cr and 30CrMnSiNi2A,” Acta Metallurgica Sinica, vol.42,no.9,pp.965-970,2006.

[12] L. Jin-Quan, Y. Li-Ming, D. Zhan-Qiang, and H. De-Wu, "Microstructure investigation of $35 \mathrm{CrMnSi}$ rod projectile penetration in to mid-carbon steel target plate," Ordnance Material Science and Engineering, vol.27, no.5, pp.20-23, 2004.

[13] Z. Xu-Ping, R. Qiang, and C. Gang, "Effect of double quenching on tensile strength of 35CrMnSi steel,” vol.26, no.5, pp.45-48, 2011.

[14] X. Yu-Xin, W. Shu-Shan, Y. Wen-Kang, and G. Zhong-Ren, "Armor-piercing experiment on fragment against sandwich plate with fiber reinforced composite cores," Acta Materiae Compositae Sinica,vol.29,no.3,pp.72-78,2012.

[15] X. Yu-Xin, W. Shu-Shan, B. Xue-Fei, and L. Yong, "Armor-piercing ultimate of tungsten alloy spherical fragment against low-carbon steel," Journal of Vibration and Shock, vol.30,no.5,pp.192-195,2011.

[16] X. Yu-Xin, W. Shu-Shan, Z. Zhe, L. Li, and Z. Xiao, "Research on armour-piercing effect of high velocity tungsten alloy fragment against medium-thick steel target,” Acta Armamentarii, vol.30,no.5,pp.259-262,2009.

[17] Curtze S, Kuokkala V T, Hokka M. "Deformation behavior of TRIP and DP steels in tension at different temperatures over a wide range of strain rates," Materials Science and Engineering A:Structural Materials Properties Microstructure and Processing,pp.124-131,2009.

[18] Z. Jun, D. Hua, T. Zheng-You, and L. Mao, "Effects of Nb and final quenching on microstructure and mechanical property of Q\&P steels,” Journal of Northeastern University, vol.34,no.1,pp.66-70,2013. 